\title{
Seriam as Exposições da Semana Nacional de Ciência e Tecnologia Museológicas?
}

\section{Would be the exhibitions of Nacional Week of Science and Tachnology Museologicals?}

DOI: 10.46814/lajdv2n5-005

Recebimento dos originais: 10/07/2020

Aceitação para publicação: 30/08/2020

Fernando Barcellos Razuck

Doutor em Educação pela Universidade de Brasília/Faculdade de Educação

Instituição: Instituto de Radioproteção e Dosimetria (IRD)

Endereço: Avenida Salvador Allende, 3773 - Barra da Tijuca, Rio de Janeiro - RJ, Brasil

E-mail: razuckdabrasilia@hotmail.com

\section{Renata Cardoso de Sá Ribeiro Razuck}

Doutora em Educação pela Universidade de Brasília/Faculdade de Educação Instituição: Faculdade de Educação/Universidade Federal do Rio de Janeiro (UFRJ)

Endereço: Avenida Pasteur, 250, Urca, Rio de Janeiro - RJ, Brasil

E-mail: razuckrenata@gmail.com

\section{RESUMO}

As exposições itinerantes de Ciência e Tecnologia (C\&T), como as que ocorrem na Semana Nacional de Ciência e Tecnologia (SCNT), apresentam cada vez mais um papel relevante no processo de Popularização da Ciência (PC). Entretanto, a sua caracterização e definição enquanto exposição museológica apresenta alguns questionamentos. Este trabalho tem por objetivo analisar a participação de uma instituição de pesquisa nesse evento e verificar, por meio da análise dos objetos, textos, materiais utilizados e por comparação com definições presentes na literatura, a sua caracterização como uma exposição museológica.

Palavras-chave: Popularização da Ciência, Exposição Museológica, Semana Nacional de Ciência e Tecnologia.

\begin{abstract}
The exhibitions of Science and Technology (S\&T), such as those in the National Week of Science and Technology (SCNT) have an increasingly important role in the Popularization of Science (CP). However, the characterization and definition as a museum exhibition presents some questions. This work aims to analyze the participation of a research institution at the event and verify, through analysis of objects, texts, materials used and by comparison with definitions in the literature, its characterization as a museum exhibition.
\end{abstract}

Keywords: Popularization of Science, museological exhibits, the National Week of Science and Technology. 


\section{INTRODUÇÃO}

Atualmente, pode-se afirmar que os museus e centros de Ciência e Tecnologia (C\&T) têm um papel central no processo de educação científica, possibilitando a Popularização da Ciência (PC) por meio das suas exposições museológicas científicas.

Isto porque, segundo Moraes (2009), a importância da PC dentro de museus se dá a partir da apropriação mediada do discurso e da cultura científica, processos estes em que se reconstroem conhecimentos e competências, contribuindo, de forma geral, para a emergência de uma cidadania formal e política.

Dessa forma, Loureiro (2003) afirma que uma exposição museológica é entendida como uma prática essencial e determinante do fenômeno museu, caracterizando-se como elemento da inter-relação com a sociedade e construindo representações.

Ou seja, entende-se assim que a existência do fenômeno museu ocorre por meio das suas exposições, por onde é possível a ocorrência da chamada PC (RAZUCK; SANTOS, 2017).

Essa discussão sobre a relevância do papel dos museus científicos no processo de PC remete a um outro questionamento, no qual se pergunta o quê viria, na verdade, a ser um museu, segundo os aspectos mostrados anteriormente. $\mathrm{E}$, mais especificamente, o que se caracterizaria como uma exposição museológica de C\&T.

Com relação à definição de museus, de forma geral, segundo o Instituto Brasileiro de Museus (IBRAM), “o museu é uma instituição com personalidade jurídica própria ou vinculada a outra instituição com personalidade jurídica, aberta ao público, a serviço da sociedade...” (BRASIL, 2010).

Então, os museus teriam como características principais a vinculação a uma instituição juridicamente reconhecida, bem como o exercício de um papel de relevância social. Além disso, de acordo com o IBRAM, para ser considerado como um museu, outras propriedades precisam se fazer presentes:

I - o trabalho permanente com o patrimônio cultural, em suas diversas manifestações;

II - a presença de acervos e exposições colocados a serviço da sociedade com o objetivo de propiciar a ampliação do campo de possibilidades de construção identitária, a percepção crítica da realidade, a produção de conhecimentos e oportunidades de lazer; III - a utilização do patrimônio cultural como recurso educacional, turístico e de inclusão social;

IV - a vocação para a comunicação, a exposição, a documentação, a investigação, a interpretação e a preservação de bens culturais em suas diversas manifestações; V - a democratização do acesso, uso e produção de bens culturais para a promoção da dignidade da pessoa humana;

VI - a constituição de espaços democráticos e diversificados de relação e mediação cultural, sejam eles físicos ou virtuais. 
Sendo assim, são considerados museus, independentemente de sua denominação, as instituições ou processos museológicos que apresentem as características acima indicadas e cumpram as funções museológicas.

Assim, de acordo com o IBRAM, apesar da necessidade de acervos, o que se observa em destaque é uma preocupação maior com a questão da utilização do seu patrimônio como recursos educacional e cultural.

Ainda na página do IBRAM é possível encontrar outras duas definições importantes, como a do Comitê Internacional de Museus (ICOM), de 1956 - podendo ser considerada como uma das primeiras definições sobre museus - e a aprovada pela sua 20ª Assembléia Geral, realizada em 2001.

Dessa forma, de acordo com o ICOM,

\begin{abstract}
Museu é um estabelecimento de caráter permanente, administrado para interesse geral, com a finalidade de conservar, estudar, valorizar de diversas maneiras o conjunto de elementos de valor cultural: coleções de objetos artísticos, históricos, científicos e técnicos, jardins botânicos, zoológicos e aquários.
\end{abstract}

Segundo essa definição, novamente a questão da relevância com relação ao processo de estudo dos seus objetos sob o enfoque cultural é observada. Pode-se também destacar a importância dada aos elementos científicos e técnicos como elementos de valor cultural.

E, por fim, conforme foi definido pela $20^{\mathrm{a}}$ assembléia do ICOM, destacam-se entre os pontos que caracterizam um museu, o fato deste ser uma instituição permanente, sem fins lucrativos, a serviço da sociedade, aberta ao público e que adquire, conserve, investigue, difunda e exponha os testemunhos materiais do homem, para educação e deleite da sociedade.

Além das instituições designadas como "Museus", são consideradas pelo ICOM algumas outras incluídas nesta definição, como:

a. instituições que conservam coleções e exibem exemplares vivos de vegetais e animais (como jardins zoológicos);

b. centros de ciência e planetários;

c. os ministérios ou as administrações sem fins lucrativos, que realizem atividades de pesquisa, educação e formação; e

d. qualquer instituição que reúna algumas características dos museus, oferecendo condições de pesquisas na área da Museologia, da educação ou da Formação.

Portanto, observa-se a variedade de características próprias que uma instituição museológica pode apresentar, dentre elas os centros de museus de ciências. 


\section{METODOLOGIA}

Partindo-se então das semelhanças e diferenças existentes nas afirmações apresentadas anteriormente sobre o que viria a ser uma exposição museológica e um museu de C\&T, este trabalho teve como objetivo acompanhar uma exposição na área das Ciências Naturais, realizada em Brasília, e caracterizá-la, ou não, como uma prática museológica.

A exposição em questão se tratava da Semana Nacional de Ciência e Tecnologia (SNCT), um evento de caráter nacional, coordenado pelo Ministério da Ciência e Tecnologia e Inovação (MCTI), por meio do seu Departamento de Popularização e Difusão da Secretaria de C\&T para a Inclusão Social, com o objetivo de "mobilizar a população, em especial crianças e jovens, em torno de atividades de ciência e tecnologia" (BRASIL, 2010a).

Acompanhou-se então a exposição apresentada pela instituição Embrapa, a coleta de dados foi feita por meio de entrevista com os expositores e coordenadores e pela análise do material apresentado.

A escolha da Embrapa se deve ao fato de ser uma empresa federal, de caráter público, e por fazer pesquisas na área da Agropecuária, que por si só abrange diversas áreas do conhecimento, dentre as quais destacam-se a Física, a Química, a Biologia e a Geologia. Sua missão seria a de "viabilizar soluções de pesquisa, desenvolvimento e inovação para a sustentabilidade da agricultura, em benefício da sociedade brasileira” (EMBRAPA, 2010).

\section{RESULTADOS}

A SNCT é um evento anual, de caráter nacional, promovido pelo MCTI e coordenado pelo Departamento de Popularização e Difusão da Ciência e Tecnologia (DEPDI).

O DEPDI, tem a função de "subsidiar a formulação e a implementação de políticas, programas e a definição de estratégias para a popularização e difusão de conhecimentos científicos e tecnológicos, nas diversas instâncias sociais e nas instituições de ensino" (BRASIL, 2010a).

A SNCT ocorre em vários pontos do país, e em 2010 ocorreu entre os dias 18 a 24 de outubro, tendo como tema principal "Ciência para o Desenvolvimento Sustentável”. Foram objetivos da SNCT de 2010 a promoção de atividades de divulgação científica, a difusão dos conhecimentos e o debate sobre as estratégias e "maneiras de se utilizar os recursos naturais brasileiros e sua rica biodiversidade com sustentabilidade, sempre de forma conjugada com a melhoria das condições sócio-econômicas de sua população" (BRASIL, 2010a). 
A Embrapa foi uma dentre as várias instituições participantes dessa semana, levando para isso as seguintes unidades de pesquisa, e suas respectivas exposições, todas pertencentes a regiões administrativas do Distrito Federal (DF), a saber:

1. Embrapa Agroenergia - "Etanol Lignocelulósico" e o "Projeto Biofrito, exposição (realizada em parceria com a Companhia de Água e Esgoto de Brasília - CAESB), que mostrava a preocupação com a reciclagem;

2. Embrapa Café - "Biorreator de Imersão temporária", exposição que mostrava a melhoria na produção de mudas de café;

3. Embrapa Cerrados - "Cerrado", exposição que dialogou sobre o uso de rochas na agricultura e biodiversidade do cerrado;

4. Embrapa Hortaliças - "Cultura Hidropônica", exposição que mostrou a questão do cultivo de vegetais por hidroponia; e

5. Embrapa Recursos Genéticos e Biotecnologia - "Sementes", exposição que focou na questão da conservação do banco de sementes (germoplasma).

O evento analisado se apresentava de forma interativa, com objetos que contam a trajetória das investigações científicas, suas aplicações, bem como o histórico e a representação dos objetos.

A grande maioria dos expositores eram os próprios pesquisadores, que tinham por intenção, mostrar a sua história, a relevância do seu trabalho e como estes podem melhorar as condições de vida e o desenvolvimento do país.

Observou-se que a Embrapa, durante Semana, esforçou-se para levar ao público exposições interativas de C\&T, que apresentam os últimos resultados de suas pesquisas. Para isso utilizou, principalmente, equipamentos em movimento, bem como a presença de objetos vivos (plantas), minerais, sempre com o objetivo de mostrar a importância que as pesquisas realizadas pela instituição têm no dia a dia da população.

Segundo os próprios expositores, a participação da instituição é fundamental para mostrar o que ela faz e qual a sua importância no contexto nacional, basicamente para a vida das pessoas. Foi o que nos contou o pesquisador C., em uma das entrevistas realizadas durante o evento:

A EMBRAPA tem uma preocupação, em fazer uma divulgação, de mostrar aquilo que ela vem fazendo, e como os resultados das pesquisas influem e contribuem para a vida das pessoas, para a melhoria da qualidade de vida, para a produção de alimentos, a preservação do meio ambiente. E a participação nesses eventos, tanto os eventos mais científicos, quanto os eventos mais voltados para os estudantes, para o público em geral, faz parte dessa preocupação da divulgação dos resultados e da popularização da ciência. Então o que interessa à EMBRAPA dentro das suas estratégias de comunicação da sociedade é exatamente mostrar como as pesquisas, como os resultados são importantes, e também uma certa prestação de contas dos recursos que a sociedade investe, e como são utilizados em benefício da própria sociedade.

Como se pode perceber, na fala do pesquisador C., existe a preocupação com a divulgação dos resultados e com a acuidade científica. Isso pode ser visto pelo fato de que, geralmente, 
participam como expositores nos eventos de $\mathrm{PC}$, os cientistas, técnicos e estagiários da própria instituição.

As observações mostraram que, mesmo em momentos em que os estagiários explicavam as pesquisas aos visitantes, estes eram supervisionados por pesquisadores e/ou técnicos da instituição para se garantir a qualidade da informação científica, mesmo quando uma linguagem mais acessível era utilizada.

A presença de pesquisadores na exposição é de grande relevância, pois assim, os visitantes se sentem mais seguros com as apresentações. Segundo a pesquisadora P.,

\begin{abstract}
Eu acho que é muito legal, assim, normalmente nas feiras, quem vem é o pessoal da área de comunicação, não necessariamente o pessoal da pesquisa. Mas eu acho superinteressante que os pesquisadores venham e fiquem perto da realidade, das pessoas, e a gente tem que saber falar as coisas com a linguagem de todo mundo, por que, afinal de contas, principalmente na EMBRAPA, quem paga as nossas contas é a população. É uma empresa pública, então, eu tenho que conseguir sim falar para que todo mundo entenda o que eu tô fazendo. Eu tento aproximar ao máximo da realidade daquela criança, do ouvinte. Por exemplo, se eles vieram, muitos jovens do Ensino Médio, eu já, até um pouco assim uma preliminar antes de você falar daquela tecnologia, você já sente um pouquinho, eu procuro entender um pouco a realidade, o que que vai ser aprendido por ele e o que não vai ser.
\end{abstract}

Os resultados mostraram ainda que os estudantes selecionados que passaram pelo "stand" pesquisado, eram pertencentes basicamente a dois grupos: os que iam à exposição por meio de excursão promovida pela escola e os que eram constituídos por visitantes que vinham com recursos próprios.

Com relação ao primeiro grupo (vindo em excursões escolares), a grande maioria tinha por característica serem estudantes do Ensino Fundamental. Com relação ao segundo grupo, a maioria estudava em escolas particulares, pertencentes tanto ao Ensino Fundamental quanto ao Médio. Nesse caso, muitos estavam visitando o "stand" pela segunda vez, na companhia de familiares.

De acordo com com o estudante S., 11 anos, pertencente ao $6^{\circ}$ ano do Ensino Fundamental,

Eu já tinha ouvido falar sim, mas sabe, num sabia direito o que era... sei que faz coisa de agricultura... mas nossa, muito legal aquela parte das sementes, tudo colorido é muito bonito. Eu gostei sim! Quero trabalhar lá um dia... será que pode?

Durante a semana, a maioria dos visitantes pertencia às escolas. Já nos finais de semana, os visitantes vinham em grupos, na maioria familiares. Além disso, observou-se que a maioria dos visitantes não conhecia o trabalho da Embrapa e mostravam-se dispostos a dialogar com os expositores sobre o conhecimento apresentado. 


\section{CONSIDERAÇÕES FINAIS}

Apesar de ser uma exposição de caráter diferenciado, a SNCT está vinculada a uma personalidade jurídica (MCTI), utiliza seus recursos com caráter educacional e de inclusão social, o que pode levar a incluí-la como uma exposição museológica.

O mais importante, entretanto, é que deve-se pensar o museu não só como uma instituição que apresenta algumas características, como a presença de acervos e exposições, mas sim como patrimônio cultural que utiliza seus recursos para aplicações de cunho educacional, bem como de inclusão social e vocação para a comunicação, exposição e a investigação.

Portanto, a prática museológica se relaciona a qualquer objeto ou foco, sendo a sua maior relevância o diálogo que firma com o público, a ponto de criar condições para que o visitante crie suas próprias representações.

Além disso, de acordo com o guia dos centros e museus de Ciência do Brasil (2009), no Distrito Federal somente duas Instituições são citadas (Jardim Botânico e o Zoológico), mostrando a grande carência desse tipo de instituição e destacando, mais ainda, a relevância do evento para a PC na região.

Especificamente com relação à Embrapa, por ser uma instituição de pesquisa, o seu acervo natural vem a ser os próprios resultados de pesquisa, que resultam de uma construção social na qual o conhecimento passado serve de base para as novas descobertas.

Por se tratar de um evento cuja maioria dos expositores pertenciam a instituições de pesquisa, nada mais natural do que considerar os seus resultados sob um valor histórico e cultural, o que remete a uma definição museológica.

Pode-se dizer que as exposições da Embrapa têm como objetivo despertar o interesse do visitante com relação aos trabalhos desenvolvidos pela instituição. Há uma grande preocupação da Embrapa em levar os resultados de suas pesquisas ao público visitante, adotando para isso uma linguagem acessível que utilize o contexto trazido pelos visitantes, ou seja, as suas realidades.

Além disso, a Embrapa procura apresentar suas pesquisas de forma interativa, o que, segundo visitantes e expositores, é importante para atrair as pessoas e isso, segundo os próprios expositores, desperta o interesse dos visitantes.

A maioria do público que visitou o "stand" de exposições da Embrapa, que estava localizado na entrada principal do evento, é de estudantes do Ensino Básico, oriundos de excursões escolares do DF e das cidades do entorno.

Com relação ao discurso da Ciência levado pela Embrapa, este se apresenta de forma recontextualizada, a fim de se encurtar a distanciamento que se encontra entre os discursos e saberes 
científico e cotidiano. Ou seja, tem-se como prática tentar traduzir o conhecimento científico de forma que seja compreensível a todos.

Entende-se então, com o resultado desta pesquisa, que a exposição proposta pela Embrapa realmente é impactante no sentido de estimular os alunos a pensarem sobre a Ciência e Tecnologia.

Um fator também observado durante a apresentação dos expositores se refere à atenção dada aos visitantes, sempre de forma solícita, e pronta para se tirar qualquer dúvida, quaisquer que fossem os expositores. Na maioria das vezes os estagiário eram acompanhados por um pesquisador ou técnico da área, o que facilitava a recontextualização.

Outro ponto que merece destaque foi o freqüente cuidado com a linguagem, de forma a expor de uma maneira inteligível às crianças e jovens visitantes.

Portanto, entende-se que o contato com o conhecimento apresentado nas exposições pode conduzir crianças e jovens a ressignificar seus conhecimentos, para além dos escolares, refletindo sobre a presença e a importância da C\&T em suas vidas.

Dessa forma, os conceitos científicos apresentados passam a apresentar novos significados, inteligíveis aos alunos, a ponto de despertar interesse, praticamente coletivo, de desenvolverem estudos e trabalhar futuramente nas áreas envolvidas com a C\&T no país.

Além disso, cabe destacar que a "Ciência" não está apenas associada à área científica, mas há todo um arcabouço que subjás o conhecimento, como os pertencentes as áreas da comunicação e administração, que inclusive foram citadas por alguns estudantes que visitaram a exposição.

Assim, tais eventos, além de aproximar a Ciência da realidade do aluno, leva à reflexão do que vem a ser "Ciência", ampliando as expectativas acerca das possibilidades de realização profissional.

\section{REFERÊNCIAS}

BRASIL. Instituto Brasileiro de Museus. Definição de Museus. Disponibilizado em < http://www.ibram.gov.br/>. Acesso em 20 de agosto de 2010.

\section{BRASIL. Departamento de Popularização e Difusão da Ciência e Tecnologia (DEPDI).} Disponibilizado em <http://www.mct.gov.br/index.php/content/view/12926.html>. Acesso em 03 de agosto de 2010a.

Centros e museus de ciência do Brasil 2009. Rio de Janeiro: Associação Brasileira de Centros e Museus de Ciência : UFRJ. FCC. Casa da Ciência : Fiocruz. Museu da Vida, 2009.
EMBRAPA.
Missão
e
Atuação.
Disponibilizado
em

<http://www.embrapa.br/a_embrapa/missao_e_atuacao>. Acesso em 10 de dezembro de 2010. 
LOUREIRO, J.M.M. Museu de Ciência, Divulgação Científica e Hegemonia. Ciência da Informação, Brasília, v. 32, n. 1, jan./abr., 2003.

MORAES, R. Incursões no discurso da ciência: a popularização da ciência nos espaços dos museus. Revista Virtual de Gestão de Iniciativas Sociais, v. 1, p. 1-14, 2009.

RAZUCK, F. B.; SANTOS, W. L. P. A Popularização da Ciência na Semana Nacional de Ciência e Tecnologia: um estudo de caso, sob o enfoque CTS, da participação de uma instituição de pesquisa. Ensenanza de Las Ciencias, v. Extra, p. 1537-1542, 2017. 